\title{
Unorthodox Electrical Energy Distribution and its Social Impact to the Azegue Slum Neighbourhood in Yaounde, Cameroon
}

\author{
Tende Renz Tichafogwe ${ }^{1 *}$, Ndzie Souga Clotaire ${ }^{2}$ \\ ${ }^{1}$ Department of Geography, Faculty of Arts, Letters and Social Sciences, the University of Yaounde 1, Cameroon \\ ${ }^{2}$ Department of Geography, Higher Teachers' Training College, the University of Yaounde 1, Cameroon
}

DOI: $10.36348 /$ SJHSS.2019.v04i09.007

| Received: 19.09.2019 | Accepted: 27.09.2019 | Published: 30.09.2019

*Corresponding author: Tende Renz Tichafogwe

\section{Abstract}

Access to electrical energy in urban slum settlement areas is a systematic challenge to the population of Cameroonian cities. This stems from the nature of the relief, deplorable living conditions and poverty. This article advances that poverty and the nature of the relief have caused the people of Azegue to indulge in unorthodox means to access electricity which has affected their social wellbeing. Data collection through questionnaire administration, observation and perception, interviews and group discussions coupled with documentary research were done. Results from findings advocate that the inadequate supply of electrical energy in Azegue has enabled the inhabitants to devise other means of survival. Some $87 \%$ of the population of Azegue lives in poverty. The neighbourhood is characterised by $20 \%$ of hills and $80 \%$ of valley slums with poor runoff and drainage. A greater part of the neighbourhood is considered prohibited for settlement hence, not fit for electrical energy supply. Some inhabitants of the area acquire energy through direct connection on electric poles without permission. Others receive their supply from neighbours as secondary source distributors. Electrical energy distribution triggers a solid social relationship amongst those engaged in the same activity.This method of social justice by the inhabitants on one hand augments solidarity and on the other produces conflicts. Considering the indispensible nature of electrical energy to the daily functioning of households, State intervention in land acquisition and the provision of social amenities is imperative in Azegue to render the area sustainable for settlement.

Keywords: Electrical energy, unorthodox distribution, slum, poverty, nature of relief, Azegue.

Copyright @ 2019: This is an open-access article distributed under the terms of the Creative Commons Attribution license which permits unrestricted use, distribution, and reproduction in any medium for non-commercial use (NonCommercial, or CC-BY-NC) provided the original author and source are credited.

\section{INTRODUCTION}

Access to electrical energy is one of the very recurrent problems in Sub-Saharan Africa in particular and Africa in general. More than 620 million people do not have access to electrical energy distributed to homes, Energy Literacy [1]. From recent statistics, just $30 \%$ of the population of Sub-Saharan Africa has access to electrical energy, World Energy Outlook [2]. Unfortunately, this situation is paradoxical as Africa is noted for having close to $300 \mathrm{GW}$ of hydro electrical potentials which permits the supply of more than two terawatts per hour each year and adequately supply the continent.

In Cameroon, access to electrical energy is a perpetual struggle. Even with the numerous potentials, the country for the past years now has been experiencing acute electrical energy shortages to which that of slums are severe, Asa Nveryuy and Saah Ndifon [3]. These shortages affect the households significantly.
After the economic crisis of 1980 , electricity crisis in Cameroon increased because the State did no longer take active part in its distribution. Owing to this resignation, several households loosed access to energy and some were involved in illegal acquisition. However, this illegal acquisition persists despite the sensitisation campaign of the AES-SONEL electricity company in Cameroon.

In the Azegue neighbourhood, access to electrical energy is a nightmare. The inadequate supply of electrical energy to households is a persistent problem to the wellbeing of the inhabitants. The area faces problems of illegal connection of electricity lines, acquiring electricity energy from neighbours and relations which is the most popular source in the area. Located in the Yaounde 2 municipality, the Azegue neighbourhood is one of the oldest and most popular areas. It is found between longitude $3^{0} 24^{\prime}$ and $3^{0} 34^{\prime}$ North to latitude $11^{0} 39^{\prime}$ and $11^{\circ} 40^{\prime}$ East of the globe. 
With a surface area of 78 hectares of land, it is bounded to the north by Madagascar, to the south by Nkolbikok, to the west by Cite Verte and to the east by Mokolo neighbourhoods (Figure 1).

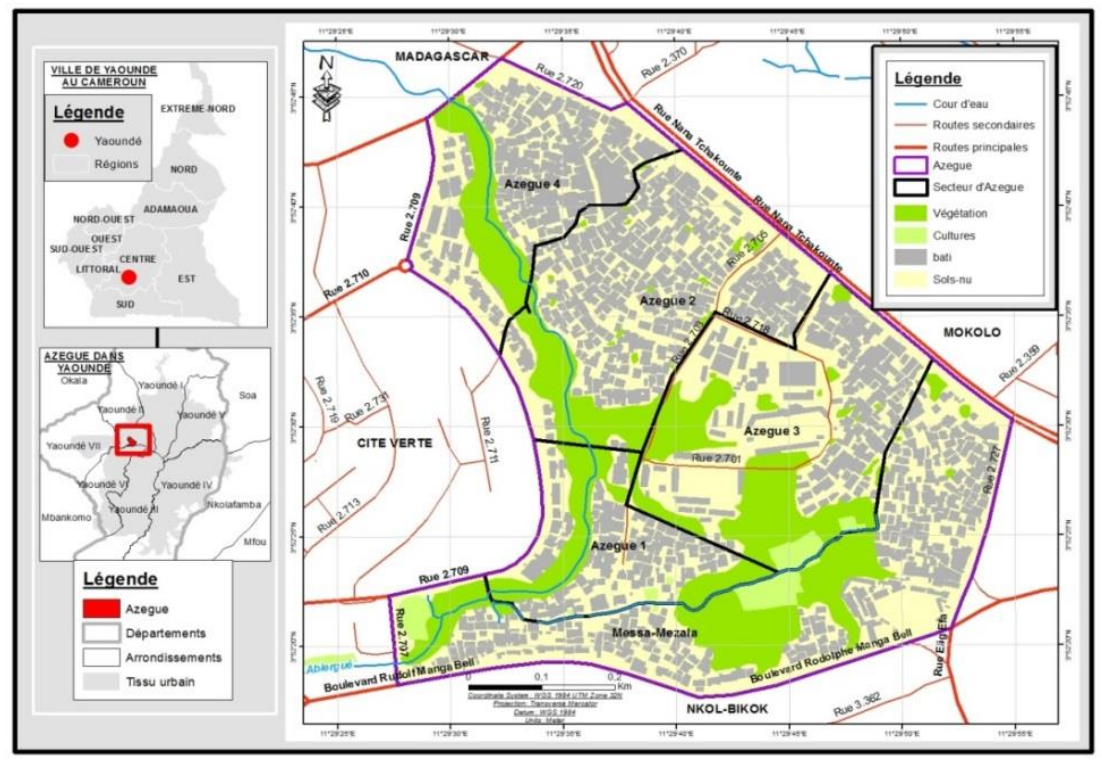

Fig-1: Location of the study area

Source: Modified by Nzie Souga from National Institute of Cartography, 2019

With the difficulties involve in electrical energy supply in Azegue, other means are used for its acquisition. This paper is aimed at revealing the difficulties involve in electrical energy acquisition and social impact on the Azegue neighbourhood and inhabitants.

\section{METHODOLOGY}

Data collection was done through a systematic approach. Through this approach, 112 questionnaires were distributed to households in order to capture data on the difficulties involved to access electrical energy in Azegue. Added to this, focus group discussions on the social bond created by the inhabitants of this neighbourhood due to the illegal practice to access electrical energy were as well done with some five groups of village associations. Furthermore, field observation was done to have a clear view of the area, identifying the make-shift houses of the people in Azegue and understanding the network involved in the acquisition of energy in the area. In order to properly analyse the dynamics involved in the social impact on the Azegue neighbourhood, data was gotten from households connected to electrical energy network. Owing to the fact that a majority of the inhabitants in this neighbourhood are illegally consuming electrical energy, field interviews were preferred to avoid false response and resistance. The class of persons interviewed in the households were above 20 years of age since issues of electrical energy were better understood by family heads. Some 112 households were questioned and the data obtained were analysed to produce results.

\section{RESULTS AND DISCUSSIONS}

Results from findings revealed that the nature of the relief, poverty and social problems have reduced the Azegue neighbourhood into a state of anarchy.

\section{The nature of relief and its influence on electrical energy supply in Azegue}

In Cameroon, water and electrical energy are being supplied by private companies. Water is distributed by Camerounaise de Eaux (CDE), while electrical energy is by ENEO. These companies function with the location of the household which needs energy or water depending on the nature of relief. Field revelations showed that the nature of the relief hinders access to electrical energy supply to Azegue.

The Azegue neighbourhood is found in a lowland area which is characterised by $20 \%$ of hills and $80 \%$ of valley slums with poor runoff and drainage. This explains why a greater part of the neighbourhood is considered as a prohibited zone for settlement hence, not fit for electrical energy supply, Bopda [4]. Article 4, of the law by the Ministry of Mines and Enrergy in 2009 restricts supply of electrical energy to areas considered risk-prone and unfit for settlement. Based on this law, the Azegue neighbourhood can only benefit from some $20 \%$ of electrical energy supply to the highland or hills in the area. With this law, any household found in the valleys were automatically not supposed to have access to electrical energy. This explains why request for electrical energy supply by some inhabitants of the valley areas were rejected by the company. Unfortunately, what is observed is that energy has been supplied to some households in the highland area who intend distribute illegally to the 
inhabitants of the valleys based on local arrangements. Such arrangements on one hand strengthen the social ties with the people, and on the other breeds conflicts. Aside the nature of the relief, poverty is also one of the factors which have hindered electrical energy supply to Azegue and thus enhance social ills in this neighbourhood.

\section{Poverty and its influence on electrical energy supply in Azegue}

The lack of means to take care of the basic necessity of an individual can be termed poverty, Fonchingong and Fonjweng [5]. Such is the case with the population of the Azegue neighbourhood who do not only lack means to afford for their daily needs but also that to pay for electrical energy supply. Field revelations in this paper propound that $36 \%$ of the population in this neighbourhood are traders while the rest $64 \%$ are shared between animal rearing, farming, commercial transport riders, and hairdressing and teaching occupations (Figure 2).

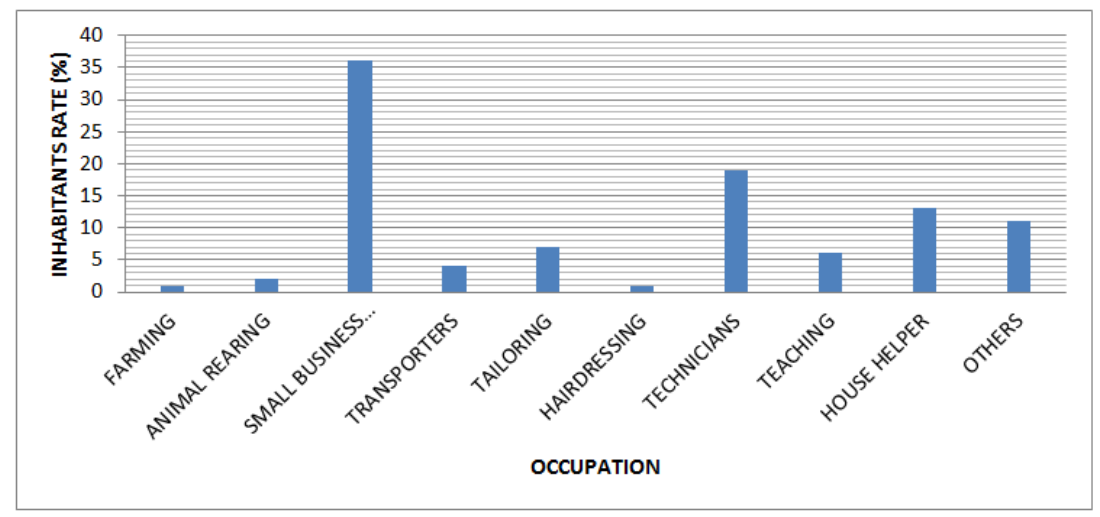

Fig-2: Occupation Distribution in Azegue Source: Field work, 2019

Generally, the Azegue inhabitants are into small business activities. They are mostly struggling people, who are into several little items such as food stuff and non-perishables in the various corners of the neighbourhood for sale. Others form the large population of scavengers who move about the city of Yaounde to sell their products. These classes of people are described as the struggling class due to the nature of their daily activities, Kengne Fodouop [6]. Other activities such as micro enterprises are involved in the sales of food stuff such as grounded beef and fish which at times are not of good quality, causing problems to the consumers to which no action is taken.
In Azegue, most youths are school drop outs who are engaged in hawking for survival, Okba Mahrez et Lainé Fréderic [7]. Aside the youths are other technicians involved in welding, motor repairs, tire mending as well as women practicing hairdressing for survival. Further results from findings revealed that close to $87 \%$ of the population of Azegue live in poverty. From figure 2, only the occupation of teaching is stable and lucrative. The others fluctuate and thus the income from these occupations varies as well. Most of the struggling population at times come home without any revenue or benefit from their daily commercial activity. The activities of the inhabitants of the Azegue neighborhood do not permit them to live a better life as seen from their monthly wages (Figure 3).

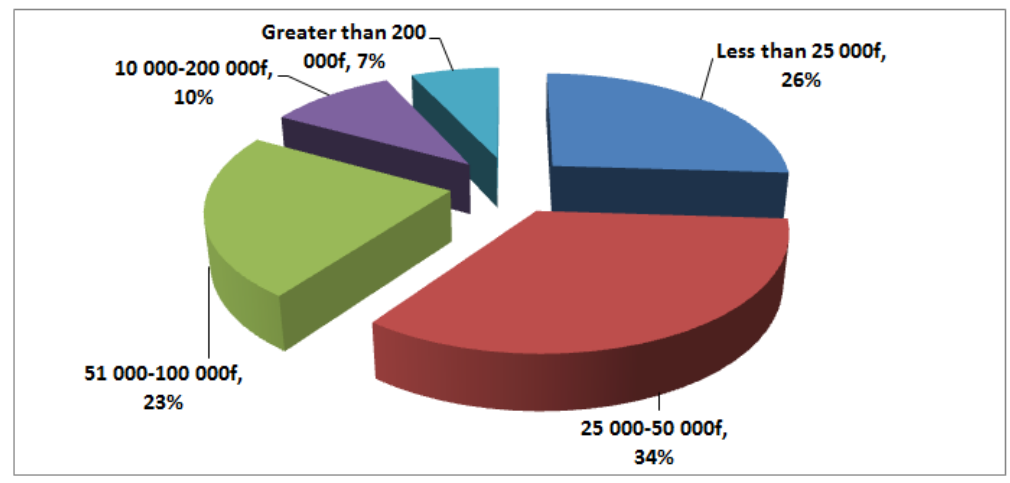

Fig-3: Average monthly wages of the Azegue Inhabitants Source: Field work, 2019 
The average monthly wage of households in Azegeue ranges from 20,000 to 200,000 frs cfa. Results from field work showed that some $34 \%$ of the inhabitants are on a monthly wage of 25,000 to 50,000 frs cfa while some $7 \%$ are on that which is more than 200,000 frs cfa. Considering the fact that the minimum average wage of a Cameroonian is 32,500, Lachaud et Al. [8], this paper can conclude that a majority of the inhabitants of Azegue live in poverty.

It is also interesting to note that a majority of the inhabitants of this neighborhood are on rents with an average of six persons per household. Therefore the merge monthly wages cannot sustain the households. All these financial difficulties trigger the active population to engage in social ills such as promiscuity and stealing, insecurity in the area. These living conditions therefore render access to electrical energy a nightmare, leading to the use of unorthodox means by the inhabitants to acquire supply. The neighborhood is constantly dirty, waste disposal is rampant and portable water is littered leading to severe consequences on the health of the inhabitants (Photo 1).

In photo 1 , the inhabitants use local wood to connect electrical energy from one household to the other. This practice is not only prohibited, but at high risk of provoking fire accidents. Further field revelations indicate that more than $85 \%$ of the houses in Azegue are make-shift structures, built out of wood or temporary materials. Such structures would always easily burst in fire accidents if any incident occurs. Added to this, the state of the structures indicate that its inhabitants would not be able to pay for electrical energy installation of 60,000 frs cfa not even the monthly cost of consumption. This has enabled those who cannot afford to devise unorthodox means of acquisition which affects their living conditions and provokes other social consequences.

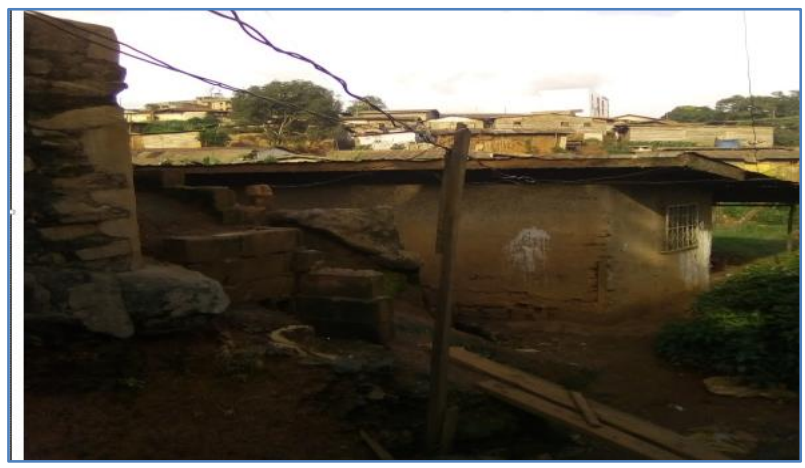

Photo-1: Unorthodox Distribution of Electrical Energy in the Azegue Neighborhood

Photo by Nzie Souga, August 2019

\section{The social consequence of access to electrical energy in Azegue}

Social integration is a function of collective action of all in a society, Fitoussi et al. [9]. Owing to this, access to electrical energy in Azegue has rather witnessed urban segregation since not everyone benefits from it and is involved in the socio-economic development of Azegue. Access to electrical energy is not only a tool to daily life and functions, but also that of social justice and cohesion. However, with the poor state of houses and living conditions to a majority of the inhabitants, elements of stigmatization, hardship, tension and conflicts are noticed in the area.

\section{The Genesis and Manifestation of Social Relationships in Azegue}

Yaounde in general and Azegue in particular's social relationships from electrical energy distribution promotes socio-economic segregation, Bopda [4]. These relationships reveal social inequality which is peculiar with Cameroonian urban areas. Social relationships are also a function of the actors and their needs. Such is the case with the Azegue neighborhood where the social relationship comes from the quest to access electrical energy on one hand, and generate income on the other. Therefore, in order to have a smooth relationship, each individual has the responsibility to maintain the bond. This has led to a new form of social relationship based on the access to electrical energy. This relationship fluctuates however from a stable to and unstable state based on the individuals concerned. This practice mostly concerns those involved in electrical energy distribution and use. This is because some inhabitants in the area live in standard infrastructure from their social background and thus are not involved in the illegal practice of electrical energy supply. Therefore they are not part of the socio-electrical energy distribution relationship hence, urban segregation. Access to electrical energy is thus a source of social consolidation and division of relationships.

\section{The role of Electrical Energy in the Consolidation or Division of Relationships}

Access to electrical energy is a factor that consolidates social relationships. The fact that it permit the individuals to constantly see and dialogue with one another improves on their acquaintance as they share their difficulties together. Field revelations showed that, some $15 \%$ of households engaged in electrical energy distribution confirm to have a solid social relationship with the others who are engaged in the same activity. Such relationships promote social cohesion and enhance the eradication of spatial inequalities that occur in the area. Nevertheless, just as in all social relationships, the risk of anti-solidarity might occur and will lead to the urban disintegration of the poor from the rich in the same neighborhood. Such irregularities are the cause of difficulties in the proper configuration of urban neighborhoods in Yaounde 2. Aside social relationships which consolidate the bond of the inhabitants in the Azegue neighborhoods, conflicts and threats are experienced as well and lead to division. 
Unequal access to electrical energy, the search for better living conditions and unemployment are some three problems that affect the social cohesion of the Azegue neighborhood. The unemployed youths that form the greater part of the active population of this area are involved in small jobs such as hawking, motorbike repairs and riding for survival. Faced with the inability to become responsible parents to take care of their households from their merge income, these youths are exposed to unorthodox methods of electrical energy acquisition and distribution. They go to an extent of tempering with household electrical meters which provokes tense social atmosphere in the area. Owing to the fact that these unemployed youths are as well school drop-outs, some insolent practices with insults and bad languages is rampant in the area. The youths are even involved in stealing as insecurity has become the other of the day in Azegue. Financial extortions and fake bills increase tension in the neighborhood. Conflicts in the area through the manipulation of electric meter reading strain the cordial relationship that exists in Azegue. From field observation, more than half of the households of Azegue do not have electric meters. It is either due to low income or from scarcity as the meters is limited.

Late payment of bills also increases the social tension and division in the Azegue neighborhood. Several disagreements occur between the illegal distributors and household owners. The several misunderstandings on the cost of energy consumption and late payment of bills lead to quarrels, insults and exchanges hence, fighting. These differences lead to conflicts and increase the division in the area. Access to electrical energy in Azegue is a nightmare. Since the population has opted for unorthodox means of acquisition, they are faced with no choice than to experience the numerous problems that occur from the illegal practice. This article therefore has shown that the electrical energy access has both increased the social relationship and tension in the Azegue neighborhoods.

\section{CONCLUSION}

With the huge potentials of energy supply in Africa, access to electrical energy is not supposed to be a problem, Andrew Scott [10]. However, distribution to all remains a nightmare. Access to electrical energy is still a persistent problem to Yaounde and Azegue. The Azegue neighbourhood x-rays a mixture of good and bad social relationship amongst its inhabitants from electrical energy distribution. In this area, illegal connections or distribution, sub-renting and other strategies put-in-place by the inhabitants leaves much to be desired. These unorthodox strategies arise from the unsecured environment of the Azegue neighbourhood characterised by anarchical distribution of electrical cables as well as less functional meters. Such practices expose the inhabitants of Azegue to several risks including fire disasters.
In Azegue, access to electrical energy has created some kind of social relationships which on one hand exhibits segregation and on the other discrimination. However, without considering the social origin and daily living conditions, some inhabitants have created a mutual social relationship. This exists due to the unorthodox distribution and acquisition of electrical energy. However, the relationship fluctuates between being cordial and strong on one hand, and tensed with division threats on the other. Therefore, electrical energy acquisition and distribution can be used as a tool for better qualitative and quantitative services to the urban population. It is thus incumbent for the State to endeavour adequate control of rules and regulations binding energy supply so as to avoid illegal distribution.

\section{REFFERENCE}

1. Energy Literacy. (2012). Essential Principles and Fundamental Concepts for Energy Education, US Department of Energy, 1000 Independence Ave SW Washington DC, 20585, 202-586-5000, Articleathttp://www1.eere.energy.gov/education/en ergy_literacy.htmi

2. World Energy Outlook. (2014). Africa Energy Outlook: A focus on Energy Prospects in Sub Saharan Africa, Paris, France, 283p.

3. Wirba, A. V., Mas' ud, A. A., Muhammad-Sukki, F., Ahmad, S., Tahar, R. M., Rahim, R. A., ... \& Karim, M. E. (2015). Renewable energy potentials in Cameroon: Prospects and challenges. Renewable energy, 76, 560-565.

4. Bopda, A. (2003). Yaoundé et le défi camerounais de l'intégration: à quoi sert une capitale d'Afrique tropicale?. CNRS.

5. Fonchingong, C. C., \& Fonjong, L. N. (2003). The concept of self-reliance in community development initiatives in the Cameroon grassfields. Nordic Journal of African Studies, 12(2), 196-219.

6. Kengne Fodouop. (2015). Cameroun jardin sacré de la débrouillardise, Editions Le Harmattan, Collection: Etudes africaines, 484.

7. Okba Mahrez et Lainé Fréderic. (2004). les jeunes des zones sensibles et leurs difficultés d'insertion professionnelle. Complément du rapport d'étude sur l'analyse économique, 279-295.

8. Inack Inack, S., Ndifo, J., \& Nkayeb, R. (1992). Pauvreté et marché du travail au Cameroun: le cas de Yaoundé. Genève, IIES, Discussion Papers, (47).

9. Fitoussi, J. P., Laurent, E., \& Maurice, J. (2004). Ségrégation urbaine et intégration sociale. Documentation française.

10. Scott, A. (2015). Building electricity supplies in Africa for growth and universal access. Background paper for Power. People, Planet: Seizing Africa's energy and climate opportunities. 